\title{
A IMAGINAÇÃO MATERIAL E A POÉTICA DAS ÁGUAS EM JOÃO CABRAL
}

\section{THE MATERIAL IMAGINATION AND THE POETICS OF THE WATERS IN JOÃO CABRAL}

\author{
Maria de Fátima Gonçalves LIMA ${ }^{74}$
}

\begin{abstract}
RESUMO: A poesia de João Cabral expressa da totalidade dos seres criados, o universo visível com seus quatros elementos: a terra, o fogo, a água e o ar. Em sua produção poética, todos estes elementos são evidenciados, especialmente a terra (metaforizada pela pedra, que por sua vez se realiza pela ação do fogo e do ar) e a água, que convive diuturnamente com o ar. Este estudo abordará o aquoso como temática central na arte de poeta.
\end{abstract}

PALAVRAS-CHAVE: Poesia brasileira moderna; Metalinguagem; Processo criativo; Metáfora.

ABSTRACT: In João Cabral formal imagination is intrinsic in speechlanguage river. The present study proposes to demonstrate formal imagination settings of poetry João Cabral and how the word artist presents its proposal in intellectual discourse, on the operation thread ideas and metaphors, plus a poetic theory marked by the laws of reasoning. This poetry expresses the fluidity of water translated by mobility metamorfoseante or metaphorical literary language.

KEYWORDS: Modern Brazilian poetry; Metalanguage; Criative process; Metaphor.

Gaston Bachelard acredita "possível estabelecer, no reino da imaginação, uma lei dos quatro elementos, que classifica as diversas imaginações materiais conforme elas se associem ao fogo, ao ar, à água ou a terra" (BACHELARD, 2002, p. 4). Ademais, afirma que toda poética deve receber componentes de elementos materiais, fundamentais para poesia. O texto poético precisa encontrar sua matéria, isto é, o elemento material que lhe proporcione sua substância.

$\mathrm{Na}$ obra cabralina, esses quatro elementos materiais estão presentes. Todavia, a terra e a água são materializadas ao longo da poética desse artista da palavra. A reiterada referência à pedra põe em evidência sua inquietação sobre o caráter de firmeza calma, densidade e condensação que deve possuir a poesia. "A terra é a substância universal, o 
caos primordial, a prima matéria separada das águas, segundo o Gênesis, levada à superfície pelo javali de Vixenu; [...] matéria de que o criador (China, Niukua) molda o homem. Universalmente, a terra é uma matriz que concebe as fontes, os minerais, os metais." (CHEVALIER \& GHEERBRANT, 1990, p.879). Desse princípio de poder, força e criação próprio da terra, a poesia de João Cabral tem como proposta a operação intelectual discursiva, o encadeamento de ideias e metáforas e uma teoria poética marcada pelas leis do raciocínio. Em contraparte, a água que precedeu a criação do cosmo e caracteriza-se como símbolo da fonte, produção e invento, é emblemática na arte de João Cabral de Melo. Infere-se dessas assertivas que a poesia desse autor situase entre "Fazer o Seco, Fazer o Úmido" (MELO NETO, 1994, p.340), aproveitando o sugestivo título do poema e o que corresponde à verdade: existe realmente uma dualidade temática e material.

Conquanto esse paralelo seja tentador, a proposta deste estudo consiste na análise específica de $O$ rio e suas relações diretas com a produção textual, com o que foi designado de "discurso do rio". E é nessa composição de ideias que está examinada a relação entre a palavra e a água. De acordo com Chevalier \& Gheerbrant (1990) os dogons faziam distinção entre a chamada "palavra seca" e "palavra úmida". Aquela foi considerada "sem consciência de si”, inda sem uma organização preconcebida, mas guarda o anseio da ordem, disposta com método; esta última desenvolveu a semente da vida. Por esse motivo, foi dada aos homens. Essa noção da palavra fecundadora, como manifestação divina de verbo que traz o germe da criação, colocado no despontar da gênese, como a primeira manifestação divina, encontra-se nas concepções cosmogônicas de muitos povos. Chevalier \& Gheerbrant (1990, p.680) explanam ainda:

Na tradição bíblica, o Antigo Testamento conhecia o tema da Palavra de Deus e o da Sabedoria, que existia antes do mundo em Deus; pela qual tudo foi criado; enviado a terra para aí revelar os segredos da vontade divina; retornando a Deus, com a missão terminada. Do mesmo modo, para São João, o Verbo estava em Deus... No pensamento grego, a palavra, o logos, significou, não apenas a palavra, a frase, o discurso, mas também a razão e a inteligência, a ideia e o sentido profundo de um ser, o próprio pensamento divino. Para os estoicos, a palavra era a razão imanente na ordem do mundo. É com base nessas noções que a especulação dos Padres da Igreja e dos teólogos desenvolveu e analisou no decorrer dos séculos o ensinamento da Escritura e, muito particularmente, a teologia do Verbo. 
Pelo exposto, a palavra, na essência ou condição própria de um ser, constitui um símbolo de sabedoria, manifestação da inteligência na linguagem, na natureza dos seres e na criação contínua do universo. Pode-se dizer ainda que a palavra tem uma estreita analogia com o mito de Palas Atena, símbolo de luta e sabedoria.

Em qualquer crença ou dogma, a palavra, o logos, exprime sempre a simbologia da mais pura manifestação do ser, do pensamento, da criação e da luta pela vida. Esta fonte de vida e conhecimento materializa-se na poética das águas de João Cabral. A poesia desse autor transfigura a imaginação formal dos rios. Porém, além das formas, o poeta inclina-se com maestria na imaginação material e, como se explicitou, a matéria discorrida é a água, que representará a palavra úmida, o verbo criador. Desta maneira, João Cabral faz um mergulho na raiz da fala, do discurso do rio da linguagem. O poema "Rios sem discurso" (MELO NETO, 1994, p.350/351) resulta desse ato de imergir nas águas da palavra, produzindo uma linguagem sobre a linguagem. Esse texto, mais do que um símbolo da linguagem poética, tornou-se um ícone da metalinguagem do discurso-rio cabralino, no sentido de trazer a imagem material da linguagem da poesia. Como matéria e poesia, ou vice-versa, este trabalho metalinguístico pode ser entendido conforme prescreve Bachelard (2002, p.3): “a matéria, aliás, se deixa valorizar em dois sentidos: no sentido do aprofundamento e no sentido do impulso. No sentido do aprofundamento, ela parece insondável, como um mistério. No sentido do impulso, surge como uma força inexaurível, como um milagre".

O curso do rio metalinguístico do poema "Rios sem discurso" é insondável e inexaurível, muitas análises já foram edificadas sobre esse ícone da poesia de João Cabral; entre elas, consideramos o artigo intitulado "Linguagem \& metalinguagem em João Cabral" (inserido na obra A metáfora crítica, 1974), de João Alexandre Barbosa. Os argumentos plausíveis marcados pela competência e experiência do ensaísta encaminharam o percurso do discurso desse estudo crítico. Também, Aguinaldo Gonçalves, com a sua obra Transição \& permanência: Miró/João Cabral: da tela ao texto (1989), muito embora não tenha analisado esse poema em particular, serviu como um espelho que direcionou teorias e reflexões aqui manifestadas. E, com base nessa indicação de rumo, pode-se aprofundar as ponderações sobre o signo linguístico realizadas por este poeta-crítico, no capítulo intitulado "Entre a mobilidade e o enigma", na primeira parte, "O Símbolo e o Ícone: duas setas para o mesmo alvo".

Saussure (1995) fez uma distinção entre língua e linguagem e, segundo seus preceitos, a palavra seria a manifestação linguística do indivíduo. Diferentemente da 
língua, que é uma função social, registrada passivamente pelo indivíduo. A fala ou parole - a palavra ou linguagem é "o ato individual de vontade e inteligência, no qual convém distinguir: as combinações nas quais o falante utiliza o código da língua para exprimir seu pensamento; $2^{\circ}$ o mecanismo psicológico que lhe permite exteriorizar essas combinações" (SAUSSURE, 1995, p. 22). Em síntese, a língua é a parte social da linguagem, exterior ao indivíduo, a linguagem tem um lado individual, mas tem também um lado social, implica ao mesmo tempo um sistema estabelecido e uma evolução: é uma instituição atual e um produto do passado, portanto tem a natureza heterogênea. Por outro lado, a língua possui uma natureza homogênea e "constitui-se num sistema de signos onde, de essencial, só existe a união do sentido e de imagem acústica, e onde as duas partes do signo são igualmente psíquicas" (p.23). Enfim, o linguista francês definiu a língua como um sistema de signos e de regras, tesouro coletivo depositado em cada cérebro, conjunto de convenções próprias de todos os locutores de um mesmo idioma, código único e homogêneo que lhes permite comunicar-se, excluindo dessa foram os outros componentes da comunicação que não o próprio código.

Ao definir o signo linguístico, Saussure chamou de signo a entidade psíquica de duas faces ou total resultado da associação de um significante (imagem acústica) e de um significado (conceito abstrato). Explicitou ainda que a aliança que une a imagem acústica ao conceito abstrato é arbitrária. “Assim, a idéia de 'mar' não está ligada por relação alguma à sequência de sons $m-a-r$ que lhe serve de significante; poderia ser representada igualmente bem por outra sequência, não importa qual" (p.81/82). Desta forma, o signo é imotivado, com exceção dos dois casos de motivações, como as exclamações e as onomatopeias autênticas. Ademais, o teórico da linguagem sustenta que a origem simbólica dessas motivações seja contestável em parte.

Émile Benveniste (1991, p.58), analisando as teorias saussureanas, entendeu que a relação entre significante e significado é realmente indissolúvel, mas não é arbitrária (pelo contrário), é necessária: “Juntos os dois foram impressos no meu espírito; juntos evocam-se mutuamente em qualquer circunstância.” Isto se realiza porque o espírito contém formas que se expressam por palavras, portanto não são vazias. Benveniste conclui que a arbitrariedade só existe entre o significante e o referente ou a realidade, já que Saussure mesmo definiu a língua como "forma" e não como "substância".

Tendo como suporte essas teorias, Aguinaldo Gonçalves, no citado capítulo de sua pesquisa, deu seu parecer sobre a natureza da linguagem poética: Ela "desrealiza" a função normativa da língua dos comunicados, mobiliza a necessária relação entre 
significante e significado além de recuperar ou nomear (indiretamente) aquilo que era apenas nebuloso no pensamento ou espírito. Desta forma, um novo mundo surge diante de nós. O processo da criação poética vai mais além de reorganização das convenções, e não significa conferir “expressividade” ao já conhecido (GONÇALVES, 1989, p.166).

Diante dessa assertiva, as conotações - cujas relações se dão por mecanismos internos de linguagem -, na teoria de Hjelmslev (1974), passam para o domínio da Semiótica. Assim, os conceitos abstratos ocorrem na esfera da virtualidade poética, na potencialidade evocadora do objeto intencional criado; originando, dessarte, as possibilidades de várias semias para um mesmo signo. Aqui, reside a natureza da palavra poética, daquela denominada acima por palavra úmida: a que tem o poder da criação e do logos - já que o signo e a realidade vão passar por um processo considerado dialético, uma vez que o signo não é a coisa, a substância, mas sim a forma. Porém, para a criação da arte literária o artista da palavra "se vale de infinitos recursos, todos eles influindo na motivação do signo linguístico enquanto material primeiro para a realização poética" (GONÇALVES, 1989, p.167).

Tendo por preceito as informações apresentadas, pode-se deduzir que o poema "Rios sem discurso" aciona a produção de imagens que conduzem as sensações visuais da fluidez do curso de um rio, com suas vozes líquidas ou como silêncio da linguagem petrificada. Tal petrificação é realizada pela ação dos olhos da medusa do isolamento e da solidão da palavra estagnada em estado de poço, metáfora do signo linguístico solitário, fechado nas suas duas faces - tendo por companhia apenas o seu sentido denotativo. Nesse imovimento, a palavra fica "estancada no poço dela mesma": é o que teoriza poeticamente "Rios sem discurso".

Este texto, ao despertar as imagens sinestésicas do silêncio, ou a comunicação limitada do poço, ou ainda a ação e as vozes das águas de um rio, dá lições da fluidez da linguagem, especialmente da linguagem poética. A poesia é a produção de um movimento complexo e intenso. A imagética do literário, nesse poema, confere a consistência das teorias linguísticas explicitadas.

Os versos "Em situação de poço, a água equivale / a uma palavra em situação dicionária: / isolada, estanque no poço dela mesma, / e porque assim estanque, estancada" (MELO NETO, 1994, p.350/351) fazem um jogo didático-poético para exprimir que, no texto artístico, o conceito saussureano do signo como entidade psíquica de dupla face (formada por significante e significado, conceito e imagem acústica), adquire uma pluralidade de sentidos. O exemplo do vocábulo “mar”, utilizado 
por Saussurre, inserido numa frase poética de João Cabral, pode emitir outras imagens que fogem da convencional. A simples referência do substantivo indica apenas a relação do conceito com a imagem acústica. Porém, a palavra "mar" inserta como uma imagem poética gera na frase uma fluidez predicativa. Alfredo Bosi (2000, p.33) sustenta que:

[...] sem a predicação, o discurso emperra. Sem discurso, a predicação perde o seu melhor apoio para sustentar-se. Pré(dic)ar é admitir a existência de relações: atribuir o ser à coisa; dizer de suas qualidades reais ou fictícias; de seus movimentos; de seus liames com as outras coisas; referir o curso da experiência. Predicar é exercer a possibilidade de ter um ponto de vista.

Desta maneira, dependendo do sentido atribuído à palavra e seus predicados, o objeto referido poderá ter outro conceito, ou outra imagem ou conceito, distante daquela convencionada.

Quanto à forma de predicação: ela se perfaz e se "vê" no desenho da frase, na sintaxe, cujo diagrama aponta para uma ordem que só "imita" o espaço do visual através da temporalidade. A disposição dos sintagmas, sobre a qual assenta todo discurso, diz o quanto a linguagem humana é, ao mesmo tempo, sequência, movimento e forma, curso e recorrência. (BOSI, 2000, p. 33).

Destarte, no poético o conceito denotativo do signo "mar" sai do estado de poço da palavra em situação dicionária e é acionado para outras margens da comunicação. Esta ação é construída por meio do desenho da frase, da sintaxe. No texto artístico, este desenho é muito complexo, mais cheio de movimento e de mais forma. O texto poético forma-se por uma teia feita de plurissignificação. Esta teia de significados que compõe o discurso que, por sua vez, constrói um tecido de enunciados integrados por níveis extremos, como o simbólico e o sonoro. No encontro destes níveis é acionada a corrente do poético, que funciona com um movimento de cargas elétricas de um condutor de sentidos. Essa corrente poética acontece por meio de artifícios formados por regularidades morfossintáticas, sinonímia, paronímia, correspondências semânticas, ritmos, metros, rimas, aliterações, assonâncias, reiterações num tecido vivo de imagens e sons. Jean Cohen assevera:

É sobre o eixo sintagmático que o verso desempenha o seu papel principal - como imagem icônica do significado. Com efeito, a sua função essencial é essa. $\mathrm{Na}$ sua relação diagramática com $\mathrm{o}$ significado, segundo a fórmula: $\left(\mathrm{Ste}_{1}=\mathrm{Ste}_{2} \rightarrow \mathrm{Sdo}_{1}=\mathrm{Sdo}_{2}\right)$. 
É o que Sausure chamava "motivação relativa" [...] O significante age como um "analogon" do significado. O "versus" ou o retorno fônico reenvia para a equivalência semântica. Na linguagem tudo é sentido. A identidade fônica significa, mas de maneira autônoma. (COHEN, 1987, p. 190-191).

A arte não pretende ser comunicativa, sua finalidade é expressão, movimento, ação; porque “[...] as frases não são linhas. São complexos de signos verbais que vêm e vão expandindo e desdobrando, opondo e relacionando, cada vez mais de somsignificante." (BOSI, 2000, p. 36). A poesia faz o signo sair do estado de poço do dicionário para ser movimentado num dis(curso) original, numa construção magistral que é ampliada a cada onda que esta linguagem polissêmica propicia.

Sobre os recursos metafóricos construídos pelo poeta, João Alexandre Barbosa (1974) analisa que são edificados por uma aproximação repetida ao núcleo básico de deflagração do texto: a relação entre discurso, enquanto qualificação de rios, a percepção da palavra enquanto integrando um universo de reflexão literária - assim o segundo verso em que "discurso-rio" e, desde já, a congeminação radical entre palavra e entidade metaforizada (BARBOSA, 1976, p.152). Nesse estudo que investiga o processo metalinguístico cabralino, vale conferir a seguinte análise sobre a segunda parte do poema:

Iniciando-se pela reiteração da imagem central com base numa estratégia frásica / vocabular de inversão / prefixação (curso $\rightarrow$ discurso), os versos terceiro e quarto apontam para uma abertura de significado importantíssima: agora o eixo ideativo é deslocado para a imagem da recomposição em que o sistema fio de água/sintaxe, da primeira parte, é retomado, ampliado, pela justaposição de uma perspectiva integralizadora que exige a participação de todos os elementos: um rio precisa de muito fio de água/para refazer o fio antigo que o fez. (BARBOSA, 1976, p.152/153).

Diante de tais indagações sobre a edificação desse texto poético, que por si só traduz toda uma teoria sobre a arte da palavra, ao transmitir saber e perícia na tessitura de um poema, faz-se necessário citar o pensamento de Hugo Friedrich (1978, p.16), que poderá explicar o ser dessa poesia altamente intelectualizada e atualíssima: “[...] uma criação auto-suficiente, pluriforme na significação, constituindo um entrelaçamento de tensões de forças absolutas, as quais agem sugestivamente em estratos pré-racionais, mas também deslocam em vibrações as zonas de mistérios dos conceitos." Nesse sentido, pode-se afirmar que a arquitetura do poema em análise torna material e 
realizada a sabedoria da palavra poética que sabe dizer, não dizendo, afirmar para negar conhece a retórica do silêncio que se esconde no espaço vazio entre o significante e o significado. Neste silêncio, está plantada a raiz da fala, que tem um reino flutuante que percorre o rio do discurso da sintaxe invisível formada por imagens, ideias, emoções, sonoridades e grafismos. No rio da sintaxe invisível flutua e oscila como as ondas, o movimento contínuo das correntes e corredeiras da linguagem, formando uma usina geradora de jogos imagéticos e uma energia poética.

O folguedo cheio de ludismo da linguagem literária que realiza os chamados jogos verbais faz, nesse texto, uma série de brincadeiras com o significante. Este flutua imageticamente sobre o seu significado (da sua função referencial), e, dele se desliga e ressurge com outro significado.

Tomando como paradigma o verso: "O curso de um rio, seu discurso-rio" (MELO NETO, 1994, p.351) e, em particular, inicialmente, o termo curso, o primeiro significado seria "ação de correr", "carreira", "movimento rápido" ou "caminho", "rumo", "rota", "percurso", "trajetória do rio" (numa função referencial). No recuo livre das ondas da linguagem, quando a palavra curso foi anexado o prefixo latino (dis) passou expressar a coordenação da linguagem ou raciocínio da ação das palavras no percurso do seu discurso-rio.

Assim, ao termo discurso foi agregada a palavra rio, formando um novo vocábulo marcado por uma hifenização e se constituindo num termo composto: discurso-rio. Nesta composição, a palavra rio pode obter uma adjetivação ou funcionar como substantivo. Na primeira hipótese, o discurso será qualificado como o rio da linguagem, isto é, tem apenas as qualidades de um rio; na segunda proposição, o discurso é um rio que flutua nas ondas da linguagem, com sua polissemia. Nesta circunstância, o discurso, ao mesmo tempo em que, qualitativamente, pertence ao rio, está inserido como propriedade do rio, designando a própria substância, o próprio ser real ou metafísico do rio. No entanto, o vocábulo discurso-rio pode ser também uma composição construída por derivação prefixal, ficando discurso, como prefixo do rio, uma vez que este último, como natureza poética, sempre esteve presente, mas não podia ser apreciado pelo sentido da visão, não se deixava ver. Cabe ao discurso proferido pelo verbo poético, a ação de exteriorizar - com as imagens e as correntes que procedem por meio de raciocínios - a sentença desse rio da linguagem e que, por sua vez, realiza a sentença-rio. 
E, então, uma nova corrente começa, determinando sempre os vários sentidos da linguagem das águas, correndo sempre para outras margens, especialmente para a terceira margem da palavra como poetizou Guimarães Rosa (1972) em “A terceira margem do rio". Estas corredeiras que oscilam de um lado e de outro do sentido das palavras põem em ação e efetivam a sentença absoluta desse rio perpétuo - a plenitude da linguagem poética.

Esta poeticidade gera uma eletrização instaurando, na sentença-rio, um momento iluminado, o instante alquímico da criação, o Fiat Lux. Esta luz que irradia da arte poética corre livre sobre o rio da linguagem.

“Os jogos de palavras são um exercício de liberdade”, é o que assevera Eduardo Prado Coelho (1968) em seu artigo denominado "João Cabral de Melo Neto: $A$ Educação Pela Pedra". A assertiva do crítico tem fundamentação sólida, e neste discurso do rio a liberdade das imagens das águas expressa os jogos imagéticos. Em João Cabral, além do tecido de imagens visuais, existe uma tessitura lúdica sonora que exprime as vozes líquidas do poema e o próprio discurso do rio:

Quando um rio corta, corta-se de vez o discurso-rio de água que ele fazia; cortado, a água se quebra em pedaços, em poços de água, em água paralítica. Em situação de poço, a água equivale a uma palavra em suitação dicionária: isolada, estanque no poço dela mesma. e porque assim estanque, estancada; e mais: porque assim estancada, muda, e muda porque com nenhum comunica, porque cortou-se a sintaxe desse rio, o fio de água por que ele discorria.

O curso de um rio, seu discurso-rio, chega raramente a se reatar de vez; um rio precisa de muito fio de água para refazer o fio antigo que o fez. Salvo a grandiloquência de uma cheia lhe impondo interina outra linguagem, um rio precisa de muita água em fios para que todos os poços se enfrasem: em frases curtas, então frase e frase, até a sentença- rio do discurso único em que se tem voz a seca ele combate.

(MELO NETO, 1994, p.350-351). 
O poema é formado por um jogo de aliterações e assonâncias. As aliterações que chamam mais a atenção na primeira parte são formadas pelo fonema / d / consoante linguodental explosiva sonora (homorgânica de t); pela consoante oclusiva linguodental surda / t /; ainda pelo fonema oclusivo, velar, surdo / q / e uma participação do / 1 /, consoante constritiva, lateral, sonora e líquida. Essa sonoridade / d /, / t /, / q /, / l / no conjunto sugere o barulho de pedaços de água se quebrando, caindo num poço sem discurso, sem corredeiras. Ao sugerir a queda de pedaços de água, o som agudo soa doído, num tilintar tão metálico, que ensurdece, operando da mesma forma que a luz, quando ofusca e obscurece a visão.

A segunda estrofe, além das aliterações concebidas a partir das citadas consoantes, exercita o som nasal dos fonemas / m /, / n /, o / r / (caracterizado como consoante alveolar, vibrante, simples, sonora e líquida) e principalmente o / f /, consoante labiodental fricativa surda, cujo timbre sugere fricção das águas em fios saindo do estado de poço, se enfrasando, esfregando, se reatando, de um para outro poço, num roçar leve em frase curtas, então frase e frase, / até a sentença-rio do discurso único. A assonância, por sua vez pode ser visualizada da seguinte forma:

\author{
a $/ \mathbf{o} / \mathbf{u} / \mathbf{i o} / \mathbf{o} / \mathbf{a} / \mathbf{e} / \mathbf{e} / \mathbf{e}$ \\ $\mathbf{o} / \mathbf{i} / \mathbf{u} / \mathbf{o} / \mathbf{i o} / \mathbf{e} / \mathbf{a} / \mathbf{u a} / \mathbf{e} / \mathbf{e} / \mathbf{e} / \mathbf{a} / \mathbf{a}$ \\ $\mathbf{o} / \mathbf{a} / \mathbf{o} / \mathbf{a} / \mathbf{a} / \mathbf{u a} / \mathbf{e} / \mathbf{u e} / \mathbf{a} / \mathbf{e} / \mathbf{e} / \mathbf{a} / \mathbf{o}$ \\ E/o/o/e/a/ ua/e/a/ua/a/a/i/i/a \\ E/i/ua/ao/e/o/o/a/a/ua/e/ui/a/e \\ $\mathbf{a} / \mathbf{u} / \mathbf{a} / \mathbf{a} / \mathbf{a} / \mathbf{a} / \mathbf{e} / \mathbf{i} / \mathbf{a} / \mathbf{a o} / \mathbf{i} / \mathbf{i o} / \mathbf{a} / \mathbf{i a}$ \\ $\mathbf{i} / \mathbf{o} / \mathbf{a} / \mathbf{a} / \mathbf{e} / \mathbf{a} / \mathbf{e u} / \mathbf{o} / \mathbf{o} / \mathbf{o} / \mathbf{e} / \mathbf{a} / \mathbf{e} / \mathbf{a}$ \\ $\mathbf{e} / \mathbf{o} / \mathbf{e u} / \mathbf{a} / \mathbf{i} / \mathbf{e} / \mathbf{a} / \mathbf{e u} / \mathbf{e} / \mathbf{a} / \mathbf{a} / \mathbf{a}$ \\ $\mathbf{e} / \mathbf{a i} / \mathbf{o} / \mathbf{e u} / \mathbf{a} / \mathbf{i} / \mathbf{e} / \mathbf{a} / \mathbf{e u} / \mathbf{e} / \mathbf{a} / \mathbf{a} / \mathbf{a}$ \\ e/u/a/o/eu/o/e/u/o/u/i/a \\ $\mathbf{o} / \mathbf{e u} / \mathbf{o} / \mathbf{e} / \mathbf{a} / \mathbf{i} / \mathbf{a} / \mathbf{e} / \mathbf{e} / \mathbf{e} / \mathbf{i o}$ \\ o/io/e/a/ua/o/eu/e/e/e/i/o/ia \\ O/u/o/e/u/io/eu/i/u/o/io \\ $\mathbf{e} / \mathbf{a} / \mathbf{a} / \mathbf{a} / \mathbf{e} / \mathbf{a} / \mathbf{e} / \mathbf{e} / \mathbf{a} / \mathbf{a} / \mathbf{e} / \mathbf{e}$ \\ u/io/e/i/a/e/ui/o/io/e/a/ua \\ $\mathbf{a} / \mathbf{a} / \mathbf{e} / \mathbf{a} / \mathbf{e} / \mathbf{o} / \mathbf{i o} / \mathbf{a} / \mathbf{i} / \mathbf{o} / \mathbf{e u} / \mathbf{o} / \mathbf{e}$ \\ $\mathbf{a} / \mathbf{o} / \mathbf{a} / \mathbf{i} / \mathbf{o} / \mathbf{u e ̂} / \mathbf{i a} / \mathbf{e} / \mathbf{u} / \mathbf{a} / \mathbf{e i a}$ \\ e/i/o/o/i/e/i/a/ou/a/i/ua/e \\ u/io/e/i/a/e/ui/a/a/ua/e/io \\ $\mathbf{a} / \mathbf{a} / \mathbf{e u} / \mathbf{o} / \mathbf{o} / \mathbf{o} / \mathbf{o} / \mathbf{o} / \mathbf{e} / \mathbf{e} / \mathbf{a} / \mathbf{e}$ \\ $\mathbf{e} / \mathbf{a} / \mathbf{e} / \mathbf{u} / \mathbf{a} / \mathbf{e} / \mathbf{a o} / \mathbf{a} / \mathbf{e} / \mathbf{e} / \mathbf{a} / \mathbf{e}$ \\ $\mathbf{a} / \mathbf{e} / \mathbf{a} / \mathbf{e} / \mathbf{e} / \mathbf{a} / \mathbf{i o} / \mathbf{o} / \mathbf{i} / \mathbf{u} / \mathbf{o} / \mathbf{u} / \mathbf{i} / \mathbf{o}$ \\ $\mathbf{e} / \mathbf{e u} / \mathbf{e} / \mathbf{e} / \mathbf{o} / \mathbf{a} / \mathbf{e} / \mathbf{a} / \mathbf{e} / \mathbf{e} / \mathbf{o} / \mathbf{a} / \mathbf{e}$
}


A presença da assonância fundamenta as vozes líquidas: em todo o poema, como pode ser visualizado acima, todas as vogais cantam a canção dos riachos: iiii, aaaa, eeee, uuuu, oooo, reiteradamente, como uma imaginação aberta, com frescor, claridade e uma alegria passarinheira, são tagarelas que gorjeiam brincando com os diamantes líquidos que moram nos sons vocálicos. Conforme Bachelard, "esses risos, esses chilreios são, ao que parece, a linguagem pueril da Natureza. No riacho quem fala é a Natureza criança" (BACHELARD, 2002, p. 35). A voz da fonte canta a arte da natureza. Do outro lado, o poético exprime semioticamente essa voz que canta e encanta àquele que pode ouvir e perceber a vida que nasce da fonte da palavra, da raiz da fala e percorre os labirínticos caminhos da sintaxe invisível desse discurso do rio cabralino.

Assim, o poema "Rios sem discurso" evoca e materializa uma rede metafórica que, como as águas, oscila como ondas, ou correntes, trazendo luz, sabedoria e doutrinas de como vencer obstáculos, lutar contra as pedras, combater os vazios e alcançar a imortalidade: esta é a sentença-rio - a mensagem da teoria poética das águas da linguagem.

A poesia desse autor transfigura a imaginação formal dos rios. Porém, além das formas, o poeta inclina-se com maestria na imaginação material e, como se explicitou, a matéria discorrida é a água, que representará a palavra úmida, o verbo criador. Desta maneira, João Cabral faz um mergulho na raiz da fala, do discurso desse rio da linguagem.

O poema metalinguístico "Rio e/ou poço" (MELO NETO, 1994, p.251) reitera a teoria das águas. O rio, não existe dúvida, figura travessia, passagem, movimento, ação e continuidade. O poço, por sua vez, tem como símbolo principal a marca do estático, mas também simboliza segredo e dissimulação da verdade, além de ser também um sinal de profundidade e silêncio. Este texto manifesta um pensamento sobre a natureza da poesia, mas também de todas as coisas e de suas relações entre si. Pode ser percebida ainda uma ponderação sobre os valores, o sentido, os fatos e princípios gerais da existência, bem como sobre a conduta e destino do homem.

Inicialmente, percebe-se que o discurso do eu lírico é dirigido para um interlocutor, que pode ser a poesia, ele mesmo ou qualquer pessoa: "Quando tu, na vertical, /te ergues, de pé em ti mesma, /é possível descrever-te / como a água de correnteza; / tens a alegria infantil. / popular, passarinheira, de um riacho horizontal / (e embora de pé estejas)" (MELO NETO, 1994, p.252). Em qualquer dessas opções, 
encontramos o mito de narciso, o que remete esta exposição crítica ao pensador Bachelard quando torna segura a ideia de que

[...] Narciso, na fonte, não está entregue somente à contemplação de si mesmo. Sua própria imagem é o centro de um mundo. Com Narciso, para Narciso, é toda a floresta que se mira, todo o céu que vem tomar consciência de sua grandiosa imagem. Em seu livro Narciso, que por si só mereceria um longo estudo, Joachim Gasquet oferece a fórmula admiravelmente densa de toda uma metafísica da imaginação (45): 'O mundo é um imenso Narciso ocupado no ato de pensar.' (BACHELARD, 2002, p. 27).

Diante desta assertiva, verifica-se que o poema "Rio e/ou poço" exprime esse olhar profundo que se estende muito para baixo ou abaixo da superfície. É um olhar de poço muito fundo, que penetra com intensidade, investiga e observa com perspicácia, tudo a sua volta. Como um poço de conhecimento, se evidencia ou se caracteriza por grande erudição e discernimento.

Parado em si mesmo, pode encontrar o céu ou o inferno, pode morrer sugado pela própria imagem da água paralítica.

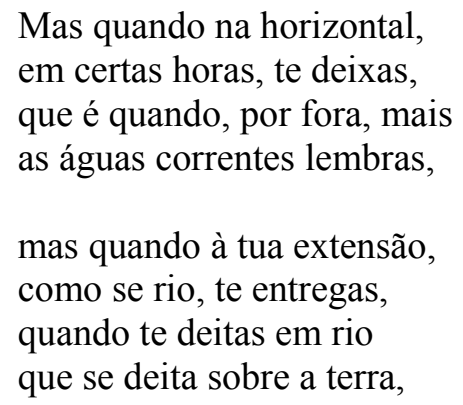

(MELO NETO, 1994, p.251).

O fluir das águas é uma canção da liberdade da poesia e do próprio ser. $\mathrm{Na}$ melodia horizontal dos versos estão as imagens do poético, assim como se percebe sinestesicamente que a vida é um entregar-se ao rio da existência, a olhar primeiro para o mundo e todas as coisas nele inseridas, inclusive a si mesmo. A linguagem pode enfrasar-se, um poço pode alcançar a sentença-rio, frase após frase, verso após verso, numa espiral que corre para outras margens, não morre em si mesmo, torna-se rio.

O ser humano é mais poço do que rio: um Narciso por natureza, nesse sentido os versos cabralinos exprimem “então, se é da água corrente, / por longa, tua aparência, / somente a água de um poço // expressa tua natureza” (p.251). 
Por este motivo, estamos mais uma vez diante de uma lição das águas, que correm para o mar buscando a imortalidade, pois a verticalidade, ou o estado de poço, quase sempre conduz à morte ou no mínimo à estagnação, porque:

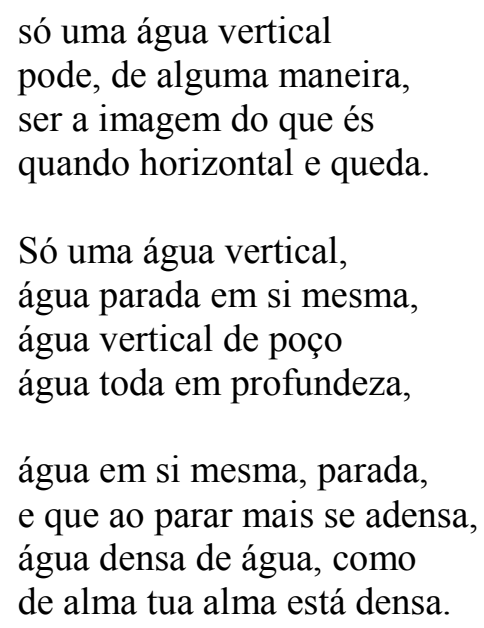

(MELO NETO, 1994, p.251-252).

O mergulho no poço de si mesmo leva o ser às águas densas e profundas que despertam os fantasmas interiores. Para fugir do suicídio, a poesia preceitua o seguimento das vozes da água corrente, cheia de ação e movimento. E claro que a existência de fonte não é um "mar de rosas", como costumam expressar: tem pedras, dificuldades. Entretanto, no encontro das pedras com as águas nascem as cachoeiras: espetáculos vivos realizados a partir desse encontro de forças da natureza.

Essa teoria da linguagem que produz um movimento contínuo está renovada no poema "Os rios de um dia" (p.352):

Os rios, de tudo o que existe vivo vivem a vida mais definida e clara; para os rios, viver vale se definir e definir viver com a língua da água. O rio corre; e, pois que com sua água, viver vale suicidar-se, todo o tempo (p.352)

A poesia da água de João Cabral alude à existência humana, lembrando também o que foi observado por Gaston Bachelard:

O conto da água é o conto humano de uma água que morre. O devaneio começa por vezes diante da água límpida, toda de reflexos imensos, fazendo ouvir uma música cristalina. Ele acaba no âmago de 
uma água triste e sombria, no âmago de uma água que transmite estranhos e fúnebres murmúrios. O devaneio à beira da água, reencontra os seus mortos, morrer também ele, como um universo submerso. (BACHELARD, 2002, p. 49).

O homem ao mergulhar no seu poço, ou nos seus rios de um dia, na falsa imagem que faz de si mesmo, está acorrendo para o "complexo de Ofélia", uma vez que, perdendo a razão, a linguagem e a palavra permanente, se vê impulsionado ao suicídio. Desorientado, erra o caminho do discurso e da vida e perde-se no caminho da morte. Sobre o "complexo de Ofélia”, Bachelard (2002, p.85) expõe:

Ofélia poderá, pois, ser para nós o símbolo do suicídio feminino. Ela é realmente uma criatura nascida para morrer na água, encontra aí, como diz Shakespeare, "seu próprio elemento". A água é o elemento da morte jovem e bela, da morte florida, e nos dramas da vida e da literatura é o elemento da morte sem vingança, do suicídio masoquista.

A perda do movimento do rio existencial manifesta-se na atração pela morte, da vida que quer morrer. "A água fornece o símbolo de uma vida especial atraída por uma morte especial" (BACHELARD, 2002, p. 50). Assim, a água é um convite à morte especial, sem a presença de uma razão que reflete a dor do não ser, do limite de seu estado de poço ou de sua palavra em estado de dicionário, sem voz, sem vez, sem discurso, sem perspectiva: aporética.

Esse ser mergulhado no seu próprio suicídio metaforiza, além do humano, a própria linguagem poética quando mergulha no vazio de um significante limitado, não flui para outras margens, não tem a força da palavra úmida, guerreira e imortal: seu discurso vazio refletirá o vazio de si mesmo:

Por isso, que ele se define com clareza, o rio aceita e professa, friamente, e se procuram lhe atar a hemorragia, ou a vida suicídio, o rio se defende. $\mathrm{O}$ que um rio do Sertão, rio interino, prova com sua água, curta nas medidas: ao se correr torrencial, de uma vez, sem alongar seu morrer, pouco a pouco, sem alonga-lo, em suicídio permanente ou no que todos, os rios duradouros, esses rios do Sertão falam claro que induz o suicídio a pressa deles: para fugir na morte da vida em poças e pega quem devagar por tanta sede. 
(MELO NETO, 1994, p.352).

A poesia de João Cabral infere a intuição heraclitiana que via na morte um devir hídrico, a morte como a própria água. Este princípio do devir incessante das coisas foi exposto no famoso fragmento de Heráclito de Éfeso (séc. V a.C.): "Não é possível entrar duas vezes no mesmo rio, nem tocar duas vezes uma substância mortal no mesmo estado; graças à velocidade do movimento, tudo vem e vai” (Fr.91, Diels). Heráclito, todavia, admitia um princípio único, subjacente ao movimento: o fogo; admitia, outrossim, uma ordem rigorosa nas mudanças, que garantia um retorno constante e periódico. Bachelard (2002) explica que Heráclito “imaginava que, no sono já, a alma, desprendendo-se das fontes do fogo vivo e universal, 'tendia momentaneamente a transformar-se em unidade"” (BACHELARD, 2002, p.59).

No poema "Na morte dos rios" (MELO NETO, 1994, p. 336/337) a morte paira como um corvo assombrando o Alto Sertão com sua marca natural. O rio seco metaforiza a morte que deixa como legado apenas a "múmia esgotada" da carência de vida a evidenciar o nada:

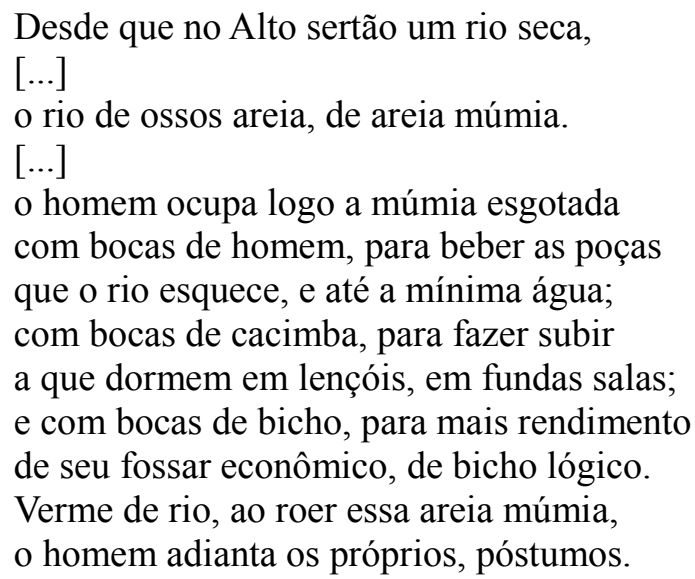

(MELO NETO, 1994, p.336/337).

Essa morte inexorável e que pode ter um fundamento cíclico, está representada pela existência de um discurso-rio vazio de criação, mas tem a faculdade de ser combatida com a palavra poética, o verbo criador de discurso-rio imortal, que atemoriza a morte, habita os vazios de muitas semias e imaginações. Esta palavra úmida se mostra revestida de "luz que brilha nas trevas", como foi associada nos cinco primeiros versículos do Evangelho de São João. Foi também esta palavra úmida e iluminada. Gilbert Durand (2001, p.154) expõe: 
Constantemente, os textos upanixádicos associam a luz, algumas vezes ao fogo, e a palavra, e nas lendas egípcias, como para os antigos judeus, a palavra preside a criação do universo. As primeiras palavras de Atum ou de Javé são um Fiat Lux. Jung mostra que a etimologia indo-européia de "aquilo que luz" é a mesma que a do termo que significa "falar", e esta semelhança também se encontraria em egípcio.

Diante do que foi explicitado, reitera-se a tese de que a vida humana/poética fica sem interrupção no tempo ou no espaço se tiver domínio sobre a palavra que desvela o silêncio que diz, não dizendo, que se encontra entre o significante e o significado. Neste lugar nasce a fonte da vida que não se interrompe em "suicídio permanente // não tem vida em poças" como está explicitado no poema "Os rios de um dia" (MELO NETO, 1994, p.352), mas fonte de "rios duradouros" (p.352), porque não têm medo do deserto vazio de palavras e de criação.

\section{REFERÊNCIAS}

BACHELARD, G. A água e os sonhos. Trad. Antonio de Pádua Denesi. São Paulo: Martins Fontes, 2002.

BARBOSA, J. A. A metáfora crítica. Língua \& Metalinguagem em João Cabral de Melo Neto. In: . A metáfora crítica. São Paulo: Perspectiva. 1974.

BENVENISTE, É. Problemas de linguística geral I. Trad. de Maria da Gloria Novak e Maria Luiza Néri. Campinas, SP: Pontes/UNICAMP, 1991.

BOSI, A. O ser e o tempo da poesia. São Paulo: Companhia das Letras, 2000.

CHEVALIER, J.; CHEERBRANT, A. Dicionário de símbolos. Trad. Vera da Costa e Silva et al. Rio de Janeiro: J. Olympio, 1990.

COELHO, E. P. João Cabral de Melo Neto: A Educação Pela Pedra. In: O reino

flutuante: exercícios sobre a razão e o discurso. Lisboa: Edições 70, 1971.

COHEN, J. A plenitude da linguagem (Teoria da Poeticidade). Trad. José Carlos Seabra Pereira. Coimbra: Almedina, 1987.

DURAND, G. As estruturas antropológicas do imaginário. Trad. Hélder Godinho. São Paulo: Martins Fontes, 2001.

GONÇALVES, A. Transição \& Permanência: Miró/João Cabral - da tela ao texto. São Paulo: EDUSP, 1994.

MELO NETO, J. C. de. Obra completa. Rio de Janeiro: Nova Aguilar, 1994.

RICOEUR, P. A metáfora viva. Trad. Dion Davi Macedo. São Paulo: Loyola, 2000.

SAMPAIO, M. L. P. Processos retóricos na obra de João Cabral de Melo Neto. Assis, SP: ILHPA/HUCITEC, 1978.

ROSA, J. G. Primeiras estórias. Rio de Janeiro: J. Olympio, 1972. 
SAUSSURE, F. Curso de linguística geral. Trad. Antônio Chelini, José Paulo Paes e Isidoro Blikstein. São Paulo: Cultrix, 1995.

Artigo recebido em 28/08/2012 Aceito para publicação em 24/09/2012 